\title{
MCDM APPROACHES IN PROPERTY INVESTMENTS: AN AHP MODEL FOR RISK ASSESSMENT
}

\author{
Chiara D'Alpaos \\ Department of Civil Architectural and Environmental Engineering \\ University of Padova \\ Padova, Italy \\ E-mail: chiara.dalpaos@unipd.it \\ Rubina Canesi \\ Department of Civil Architectural and Environmental Engineering \\ University of Padova \\ Padova, Italy \\ E-mail: rubina.canesi@gmail.com
}

\begin{abstract}
When the future is uncertain and investments are durable and illiquid the decision to invest at a certain time contingent to new information to come as well as the correct assessment of risks are a key issues especially in times of global financial crisis. The existence of a well-functioning capital market allows investors with different time patterns of income and desired consumption to agree on whether real estate investment projects should be undertaken. In order to make the decision, investors need to measure risks and identify the relationship between risks borne and risk premiums demanded: developers have to determine how much risk they can tolerate, the return they need and its timing. Real estate development is de facto a dynamic multiphase process involving land development, followed by residential and/or commercial development, ending with the eventual marketing phase through the sale or leasing of the completed site. The three phases of the housing industry are interrelated, and each stage involves various risks, differently allocated between landowners, land developers, and homebuilders.

The aim of this paper is to provide an operational framework to address risk and uncertainty by an integrated approach. More precisely, the paper proposes a procedure for a synthetic risks assessment that, based on the AHP model, will help investors to manage risk exposure and opportunities in property investments. Numerical examples on urban development projects are presented in order to test the effectiveness of the AHP model in supporting decisions and adapting strategies to a permanently changing environment.
\end{abstract}

Keywords: Risk Assessment, Property Investments, AHP.

\section{Introduction}

When the future is uncertain and investments are durable and illiquid the decision to invest at a certain point in time, contingent to new information to come, as well as the correct assessment of risks are a key issues especially in times of global financial crisis. The existence of a well-functioning capital market allows investors with different time 
IJAHP Article: Mu, Saaty/A Style Guide for Paper Proposals To Be Submitted to the International Symposium of the Analytic Hierarchy Process 2014, Washington D.C., U.S.A.

patterns of income and desired consumption to agree on whether real estate investment projects should be undertaken. Investors need to know how to measure risks and identify the relationship between risks borne and risk premiums demanded. Risk affects investments and cannot be fully eliminated. Increases in both idiosyncratic and systematic risk lead developers to delay real estate investments because they feel not confident in the estimated returns and the assessment of the project's riskiness. Investors have indeed to determine how much risk they can tolerate, the return they need and its timing.

Aim of the paper is to provide a theoretical and operational framework to address risk and uncertainty in real estate investment valuation procedures. The paper proposes a model for risks assessment that help to evaluate risks and opportunities of real estate assets and property investments taking into consideration different aspects of the project and related risks (market risk, valuation risk, market growth risk, operating risk, etc.). Real estate development is de facto a multiphase process involving land development, followed by residential and/or commercial development, ending with the eventual marketing phase of the development through the sale or leasing of the completed site. Although these phases of the housing industry are interrelated, each stage involves various risks which are differently allocated between landowners, land developers, and homebuilders. More rigorous risk assessment measures within the property investment industry are here designed to operate initially at the level of the individual asset and then extended to the framework drawn from conventional theory which operates primarily at the portfolio level. In order to make an overall assessment of the investment riskiness, it is here provided an overall risk scoring model that allows to classify real estate investments' risk.

\section{Literature Review}

Aim of this paper is to propose and discuss operative approaches to address risk and help financial managers and investors to cope with risk in practical situations. Academics have longly debated on the difference and the relationship between risk and uncertainty (Kelliher and Mahoney, 2000; Adair and Hutchison, 2005). In conventional investments and finance, the risk associated with an asset is usually defined as the volatility, quantified through the variance or standard deviation of its returns. Other authors, though, suggest that both risk and uncertainty cannot be defined operationally but only intuitively: valuers can only try to define operationally the perception of uncertainty (Lorenz et al. 2006). Chen and Khumpaisal (2009), investigating the correlation that exists between risk and investment projects in real estate development, underline that risk can strongly influence all related investment performances at all stages of the entire lifecycle of properties. A large number of contributions in the literature were devoted to risks classification in property investments (Huffman, 2002; Adair and Hutchison, 2005; Chen and Khumpaisal, 2009 ).

In the literature the contributions on risk management and interpretative models are numerous and well developed, but, conversely, the valuation of risks in real estate investments is often left to the sensitivity and the discretion of valuers. Differently from other financial investments, real estate market operators still do not have specific methodologies for measuring risk. This circumstance is not due to lack of interest by real estate operators, but to the difficulties of implementing tools developed for assessing 
IJAHP Article: Mu, Saaty/A Style Guide for Paper Proposals To Be Submitted to the International Symposium of the Analytic Hierarchy Process 2014, Washington D.C., U.S.A.

risks in financial investments, which need to be adapted to the specificities of property investments.

\section{Hypotheses/Objectives}

In order to fill the gap in the existing literature and provide real estate practitioners with specific tools to be adopted in risk assessment of property investments, we provide an operational framework to address risk and uncertainty by an integrated approach. We illustrate risk assessment procedures and introduce risk measures that can be easily understood by third parties and applied to different property types. We focus on economic risks and mainly address Market Risks (Mr) and Real Estate Operating Risks (MROr). It is rather intuitive that the former are affected by financial markets and macroeconomics, while the latter are strongly related to property investments and more specifically to real estate development investment projects. The aim of this paper is to provide an ex-ante valuation model to address risk and uncertainty in property investment decisions. Our main objective is rather to provide research tools that reveal the riskiness of a property investment than to provide an interpretative model.

\section{Research Design/Methodology}

Rigorous risk assessment measures, based on mathematical algorithms, are here presented. Specifically, we propose an overall risk scoring model to classify property investments' riskiness (Ir). $\mathrm{Mr}$ are grouped into three main categories: Capital Market risk (CMr); Valuation risk (Vr); Market Growth Rate risk (MGRr). While REOr are subdivided into six categories: Operating risk (Or); Development risk (Dr); Leasing risk (Lr); Leasehold risk (LHr); Leverage risk (LVr); Tax risk (Tr). We defined the above risk components and relative measures according to the literature and experts in real estate investments. We determined each risk component by implementing the mathematical algorithms provided. Then, according to a pool of experts and financial managers' judgments, we defined the thresholds to classify each risk component as conservative, moderate, aggressive. We determined the thresholds through focus groups and majority rule ordering. In order to make an overall assessment of the investment riskiness, we provided an overall risk scoring model that allows investors to classify real estate investments' risk. We implemented the AHP model to rank the overall riskiness of real estate investments. We obtained the weights/priorities according to the eigenvalue approach to pairwise comparisons (Expert Choice Software). We organized focus groups and obtained judgments by industry experts and realtors (majority rule ordering) in an open group process. Dynamic discussion was used while constructing the hierarchy and providing judgments by mutual agreement and revision of views. As the focus groups determined the important set of variables, they had better confidence in the relevance of their judgments. Whether they emerged, inconsistency problems were solved through judgments revision and consensus procedures.

\section{Data/Model Analysis}

The hierarchy is represented in Figure 1 and judgment matrices are illustrated in Figure 2. Sensitivity analysis was performed on the overall priority vector and on the single judgment matrices at each hierarchical level. Finally numerical examples were also implemented to clarify applications of the above algorithms and test the assessment 
IJAHP Article: Mu, Saaty/A Style Guide for Paper Proposals To Be Submitted to the International Symposium of the Analytic Hierarchy Process 2014, Washington D.C., U.S.A.

model's predictions on stylized case studies. As an example we considered the case where an investor has the opportunity to invest in a real estate development project and needs to determine related risks to make the decision. The project consists of the construction of a new office building, placed in Milan Hinterland.

The results enhanced the decision-making process and highlighted that, though an investment may prove to be ex-ante a positive Net Present Value project, ex-post this might not be the case because some of the investment risks are aggressive and not conservative or moderate.

\section{Limitations}

We provide mathematical algorithms, adaptable and interpretable, that can be generally applied in real estate investments. The proposed model can be easily understood by third parties and applied to different property. The results are easy to interpret and transparent. Risk measures may be dependent on the investment type (e.g. new development, renewal, etc.) and the properties in question (office building, residential building, etc). Therefore in order to be accurate, market analysis ( e.g. vacancy, market absorption, etc.) must be obviously adapted to the particular location and economic cycles. In particular, tax risk and leasehold risk must be carefully determined according to the investor's profile. As far as the scoring model is concerned, it is worth note that the weighting has been identified with reference to the Italian scenario, and similarly the classification of risks as conservative, moderate or aggressive.

\section{Conclusions}

The primary risk to investors is that the investment, ex-post, may be a negative Net Present Value project. Risks evaluation is often left to the sensitivity and discretion of valuers, as a consequence developers may delay or abandon real estate investments because they feel not confident in the assessment of the project's riskiness. In this respect, the paper aims to provide an operational framework to address risk and uncertainty by an integrated approach, that encourages the use of analytical tools to define a transparent risk scoring system that can be easily understood and interpreted by real estate investors and practitioners. The risk assessment model here proposed may have interesting effects in terms of risk management strategies. Each investment criteria (e.g. market impact, value distribution, etc.) can be in fact related to a specific risk measure, therefore the investor can revise or adapt investment and management strategies in order to reduce a specific risk component to acceptable reliance level (in accordance to his risk attitude) and in turn increase the economic performance of the investment.

\section{Key References}

Adair, A. \& Hutchison, N. (2005). The reporting of risk in real estate appraisal property risk scoring. Journal of Property Investment \& Finance, 23(3), 254-68.

Chen, Z. \& Khumpaisal, S. (2009). An analytic network process for risks assessment in commercial real estate development. Journal of Property Investment \& Finance, 27(3), 238-258.

Huffman, F.E. (2002). Corporate real estate risk management and assessment. Journal of Corporate Real Estate, 5(1), 31-41. 
IJAHP Article: Mu, Saaty/A Style Guide for Paper Proposals To Be Submitted to the International Symposium of the Analytic Hierarchy Process 2014, Washington D.C., U.S.A.

Kelliher, C.F. \& Mahoney, L.S. (2000). Using Monte Carlo simulation to improve longterm investments decisions. The Appraisal Journal, 68(1), 44-56.

Lorenz, D., Trück, S. \& Lützkendorf, T. (2006). Addressing risk and uncertainty in property valuations: a viewpoint from Germany. Journal of Property Investment \& Finance, 24(5), 400-433.

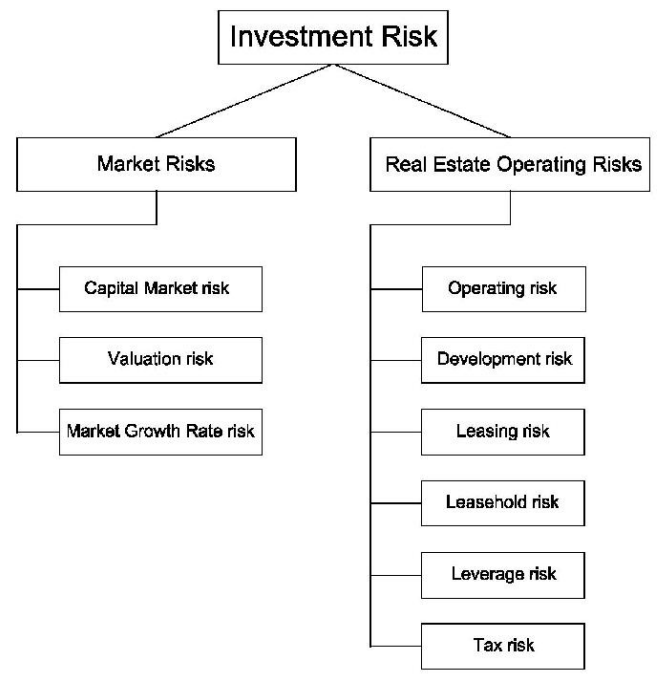

Figure 1: Hierarchy.

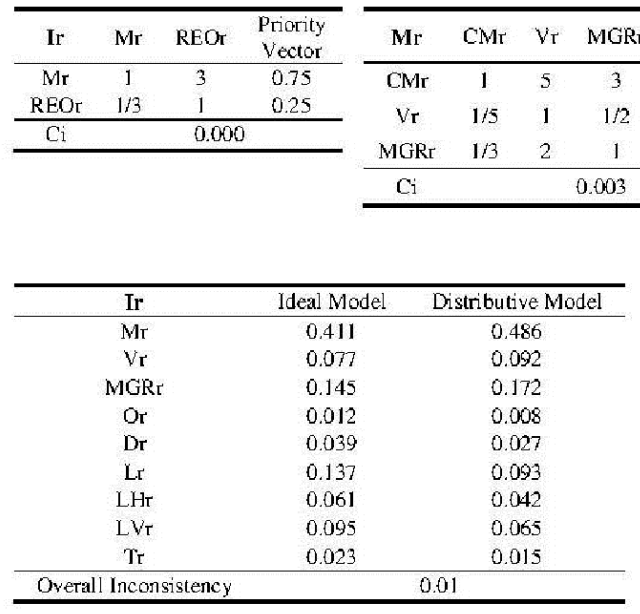

Figure 2: Judgment matrices. 